Gut, 1983, 24, 38-41

\title{
Association of primary sclerosing cholangitis with HLA-B8
}

\author{
R W CHAPMAN, * Z VARGHESE, R GAUL, G PATEL, \\ N KOKINON, and SHEILA SHERLOCK
}

\begin{abstract}
From the Departments of Medicine, Histopathology and Nephrology, Royal Free Hospital, Hampstead, London
\end{abstract}

SUMmARY The frequency of HLA antigens was studied in 25 patients with primary sclerosing cholangitis and compared with a control group of 561 kidney donors. Fourteen patients also had ulcerative colitis. A significant increase in the frequency of HLA-B8 (60\%) was found in the primary sclerosing cholangitis patients compared with controls $(25 \%)(\mathrm{p}<0.001)$. HLA-B8 was found in eight patients with ulcerative colitis. The frequency of HLA-B12 was significantly decreased $(8 \%)$ compared with controls $(30 \%)(p<0.02)$. Piecemeal necrosis was observed on liver histology in $66 \%$ of HLA-B8 positive and 50\% of HLA-B8 negative patients. Low titres of serum autoantibodies were frequently found in the primary sclerosing cholangitis group but did not correspond to the presence of HLA-B8. Raised serum concentrations of IgM and IgG were not related to HLA-B8. This study has shown that in patients with primary sclerosing cholangitis there exists a disease susceptibility gene closely associated with the B locus of the major histocompatibility complex which may be modified by other factors such as ulcerative colitis. Patients with ulcerative colitis and HLA-B8 may be particularly liable to develop primary sclerosing cholangitis.

Primary sclerosing cholangitis is an uncommon disease characterised by an intense inflammatory fibrosis usually involving the whole biliary system. ${ }^{1}$ The aetiology of this disorder is unknown, although it is closely associated with ulcerative colitis which coexists in approximately two-thirds of patients with primary sclerosing cholangitis. ${ }^{1}$

The associations between certain human leucocyte histocompatibility (HLA) antigens and an increased risk of certain diseases have recently been identified. HLA-B8 and HLA-DRW3, for example, have been closely associated with diseases involving immunological dysfunction such as autoimmune chronic active hepatitis. ${ }^{2}$ HLA-A3 has been closely associated with idiopathic haemochromatosis. ${ }^{3}$

The purpose of the present study was to investigate possible associations between the HLA system and patients with primary sclerosing cholangitis, with and without coexisting ulcerative colitis.

\footnotetext{
* Address for correspondence: Dr R W Chapman, John Radcliffe Hospital, Headington, Oxford.

Received for publication 13 April 1982
}

\section{Methods}

\section{PATIENTS}

Twenty-five consecutive patients (17 men and eight women) with primary sclerosing cholangitis who were admitted to the Royal Free Hospital for investigation were studied. The diagnosis was based on accepted criteria - namely, the demonstration of multiple strictures in the biliary system, the absence of previous biliary tract surgery, and the exclusion of bile duct cancer by at least two years' follow-up. ${ }^{1}$

Fourteen patients (10 men and four women) were also suffering from ulcerative colitis; no patient had Crohn's disease. One non-colitic male patient also had chronic pancreatitis, diabetes, and angioimmunoblastic lymphadenopathy and another noncolitic had chronic glomerulonephritis. None of the patients had a family history of primary sclerosing cholangitis or ulcerative colitis.

Serum immunoglobulins and autoantibodies were estimated. All patients included in the primary sclerosing cholangitis group were mitochondrial antibody negative. In addition, percutaneous liver biopsies were performed in all the patients using 
Menghini needles. The presence or absence of piecemeal necrosis on liver histology was assessed by one experienced observer (RG) who was unaware of the HLA-status of the patients. If present, the degree of piecemeal necrosis was assessed as mild, moderate, or severe. ${ }^{4}$

Control data were obtained by HLA typing 561 unrelated cadaveric kidney donors from the London area.

Tissue typing for 14A and 16B locus antigens was performed on peripheral blood lymphocytes using a standardised microcytotoxicity assay ${ }^{5}$ and international workshop sera.

The chi-squared test was used to analyse the results. In order to correct for derived probabilities the $p$ values were multiplied by 30 (the number of HLA alleles tested).

\section{Results}

The frequencies for particular HLA-A and B locus antigens in the patients with primary sclerosing cholangitis and controls are shown in Table 1 . In primary sclerosing cholangitis patients there was a significant increase in the frequency of HLA-B8 $\left(60 \%\right.$ vs $25 \% ; \chi^{2}=15 \cdot 1 ;$ corrected $\left.p<0.001\right)$ compared with control patients. In addition, the frequency of HLA-B12 was significantly decreased in primary sclerosing cholangitis patients $(8 \%$ vs $30 \% ; \chi^{2}=5.7$; corrected $\mathrm{p}<0.02$ ) compared with controls. HLA-B12 was not found in any patient who possessed HLA-B8. Nine of 10 patients who were found to have HLA-A1 also possessed HLAB8. HLA-B8 was found in $57 \%$ of the primary sclerosing cholangitis patients with ulcerative colitis and HLA-B12 in only $7 \%$.

There were no significant differences between the groups in the frequency of the remaining $A$ and $B$ locus antigens.

The concentrations of serum immunoglobulins IgM and IgG were not significantly different in HLA-B8 positive and negative patients (Figure). Similarly, no differences were observed with regard to the presence of low titres of antinuclear factors and smooth muscle antibody (Table 2).

Two-thirds of the HLA-B8 positive patients showed some degree of piecemeal necrosis on liver biopsy (Table 3). Piecemeal necrosis was also seen, however, in half of the HLA-B8 negative group. The difference between the groups was not significant.

\section{Discussion}

This study has shown that in primary sclerosing cholangitis there is an increased frequency of HLA-
Table 1 HLA antigens in patients with primary sclerosing cholangitis and in controls

\begin{tabular}{|c|c|c|c|c|}
\hline \multirow[b]{2}{*}{ HLA locus } & \multicolumn{2}{|c|}{ PSC patients (25) } & \multicolumn{2}{|c|}{ Controls (561) } \\
\hline & (no.) & (\%) & (no.) & (\%) \\
\hline Al & 10 & 40 & 184 & 33 \\
\hline A2 & 12 & 48 & 288 & 51 \\
\hline A3 & 4 & 16 & 163 & 29 \\
\hline AW23 & 1 & 4 & 7 & 1 \\
\hline AW24 & 3 & 12 & 83 & 15 \\
\hline A25 & $\mathbf{0}$ & 0 & 12 & 2 \\
\hline A26 & 2 & 8 & 26 & 5 \\
\hline A11 & 2 & 8 & 69 & 12 \\
\hline A28 & 4 & 16 & 56 & 10 \\
\hline A29 & $\mathbf{0}$ & $\mathbf{0}$ & 58 & 10 \\
\hline AW30 & 2 & 8 & 28 & 5 \\
\hline AW31 & 4 & 16 & 16 & 3 \\
\hline AW32 & 3 & 12 & 38 & 7 \\
\hline AW33 & 2 & 8 & $\mathbf{0}$ & 0 \\
\hline B5 & 3 & 12 & 44 & 8 \\
\hline B7 & 3 & 12 & 141 & 25 \\
\hline B8 & $15^{*}$ & 60 & 140 & 25 \\
\hline B12 & $2+$ & 8 & 170 & 30 \\
\hline B13 & 0 & 0 & 18 & 3 \\
\hline B14 & 3 & 12 & 58 & 10 \\
\hline B15 & 2 & 8 & 83 & 15 \\
\hline BW16 & 1 & 4 & 39 & 7 \\
\hline B17 & 1 & 4 & 58 & 10 \\
\hline B18 & 3 & 12 & 30 & 5 \\
\hline BW21 & 0 & 0 & 22 & 4 \\
\hline BW22 & 2 & 8 & 26 & 5 \\
\hline B27 & 5 & 20 & 50 & 9 \\
\hline BW35 & 2 & 8 & 90 & 16 \\
\hline B37 & 0 & 0 & 20 & 4 \\
\hline B40 & 3 & 12 & 62 & 11 \\
\hline
\end{tabular}

* Significantly increased in primary sclerosing cholangitis patients compared with controls.

+ Significantly decreased in primary sclerosing cholangitis patients compared with controls $(p<0.02)$.

B8. The presence of HLA-B8 has previously been shown to be associated with diseases involving immunological dysfunction ${ }^{3}$ including chronic active hepatitis, coeliac disease, myasthenia gravis, and sicca syndrome. ${ }^{3}$ HLA-B8 appears to be associated with factors which promote an increased immunological response to a variety of antigens. ${ }^{6}$ It has been suggested that HLA-B8 may be linked to genes controlling antigen non-specific suppressor cells, with subsequent failure of a normal suppressor cell response. ${ }^{3}$ Primary sclerosing cholangitis has not previously been considered to be an autoimmune disease, but it is interesting that the frequency of HLA-B8 (60\%) observed in this study is comparable with the frequency found in a number of studies of autoimmune chronic active hepatitis. ${ }^{23-10}$ In this study the frequency of HLA-DRW3 was not determined. This antigen is closely associated with HLA-B8 through linkage disequilibrium ${ }^{11}$ and it is 

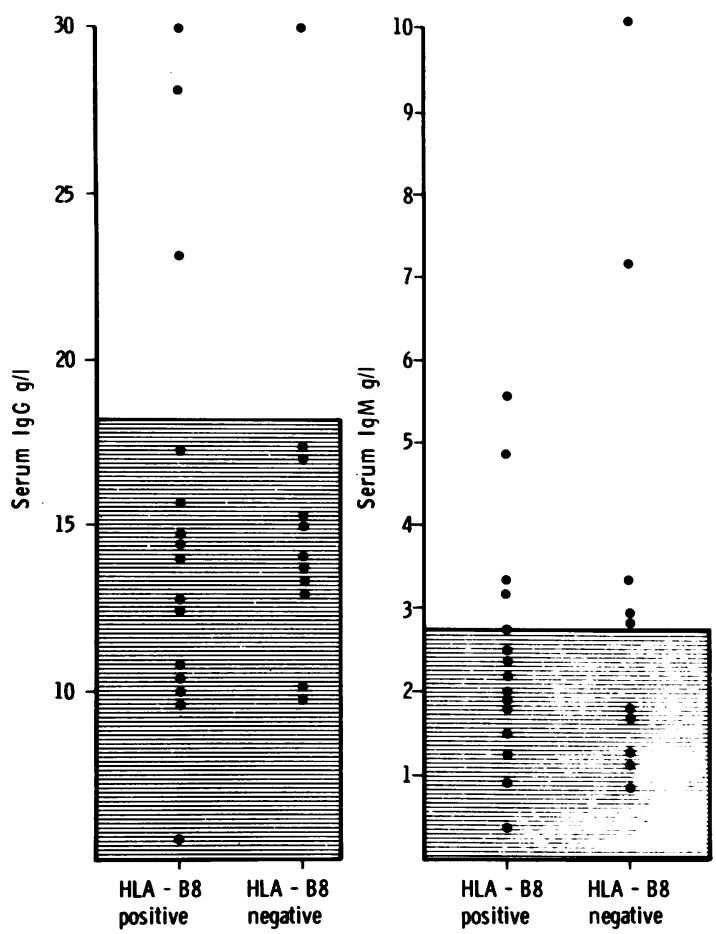

Figure Concentrations of $\operatorname{IgM}$ and $\operatorname{IgG}$ in the primary sclerosing cholangitis patients. Shaded area represents the normal range.

probable that there is an increased frequency of HLA-DRW3 in primary sclerosing cholangitis.

The explanation of the low frequency $(8 \%)$ of 12 found in the primary sclerosing cholangitis patients is not clear, as the frequency of HLA-B12 has been observed to be normal in previous studies of patients with autoimmune chronic active hepatitis. ${ }^{2} 3$ 8-10 HLA-B12, like HLA-B8, is associated with heightened immune responses. ${ }^{36}$ None of our

Table 2 Serum autoantibodies in primary sclerosing cholangitis

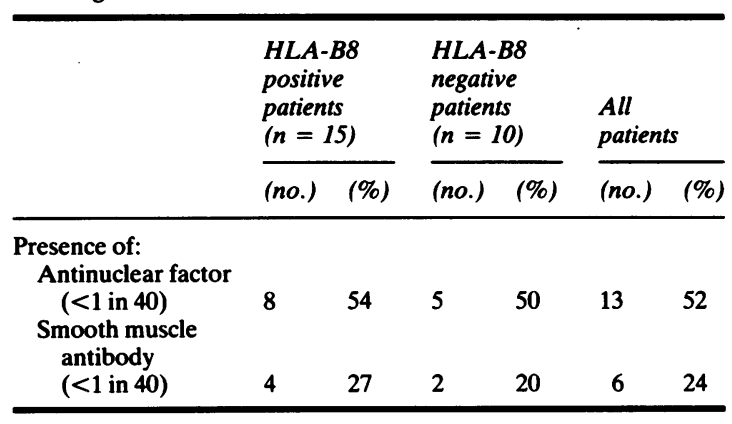

Table 3 Piecemeal necrosis in primary sclerosing cholangitis

\begin{tabular}{|c|c|c|c|c|c|c|}
\hline \multirow{2}{*}{$\begin{array}{l}\text { Degree of } \\
\text { piecemeal } \\
\text { necrosis }\end{array}$} & \multicolumn{2}{|c|}{$\begin{array}{l}\text { HLA-B8 positive } \\
\text { patients } \\
(n=15)\end{array}$} & \multicolumn{2}{|c|}{$\begin{array}{l}\text { HLA-B8 negative } \\
\text { patients } \\
(n=10)\end{array}$} & \multicolumn{2}{|c|}{$\begin{array}{l}\text { All } \\
\text { patients } \\
(n=25)\end{array}$} \\
\hline & (no.) & $(\%)$ & (no.) & (\%) & (no.) & (\%) \\
\hline None & 5 & 33 & 5 & 50 & 10 & 40 \\
\hline Mild & 5 & 33 & 4 & 40 & 9 & 36 \\
\hline Moderate & 5 & 33 & 0 & & 5 & 20 \\
\hline Severe & 0 & & 1 & 10 & 1 & 4 \\
\hline
\end{tabular}

patients with primary sclerosing cholangitis possessed both antigens, which have been shown to act synergistically in stimulating serum autoantibody production. $^{6}$

We were unable to show any association between the presence in the serum of low titres of smooth muscle antibody and antinuclear factor and HLAB8. In contrast with patients with autoimmune chronic active hepatitis the presence and titre of these circulating autoantibodies has been shown to correlate closely with HLA-B8. ${ }^{36}$

It has been suggested that primary sclerosing cholangitis and primary biliary cirrhosis represent variations of the same disease spectrum. ${ }^{12}$ An increased frequency of HLA-B8 has not been observed, however, in a study of patients from our unit with primary biliary cirrhosis. ${ }^{14}$ From the results of this study it seems likely that primary sclerosing cholangitis and primary biliary cirrhosis are aetiologically distinct diseases.

The increased frequency of HLA-B8 was similar in the primary sclerosing cholangitis patients with and without coexisting ulcerative colitis. A number of studies have shown that the frequency of HLAB8 is not increased in patients with ulcerative colitis alone. ${ }^{15} 16$ The factors which lead to patients with ulcerative colitis developing chronic liver and biliary disease are unknown. The presence of HLA-B8 may render an individual suffering from ulcerative colitis more susceptible to the developent of chronic liver disease. It is also possible that the presence of HLA-B8 determines that the liver disease pursues a more aggressive course. This mechanism is thought to be of importance in patients with alcoholic liver disease who are also HLA-B8 positive. ${ }^{17}$ Some evidence for the latter possibility is the trend seen in this study for piecemeal necrosis to be more severe and more frequently seen in the HLA-B8 positive group. HLA-B8 may prove to be a useful marker of those patients with ulcerative colitis who are liable to develop chronic liver disease.

It appears that in primary sclerosing cholangitis, 
as in autoimmune chronic active hepatitis, there is a disease susceptibility gene associated with the HLAB8 locus of the major histocompatibility system which may be modified by other factors such as ulcerative colitis.

We are grateful to Dr J A Sacks for providing control data and to Miss Diana Wilson for typing the manuscript.

\section{References}

1 Chapman RW, Arborgh BA, Rhodes JM et al. Primary sclerosing cholangitis - a review of its clinical features, cholangiography and hepatic histology. Gut 1980; 21: 870-7.

2 Mackay IR, Tait BD. HLA associations with autoimune-type chronic active hepatitis: identification of B8-DRW3 haplotype by family studies. Gastroenterology 1980; 79: 95-8.

3 Eddlestone ALWF, Williams R. HLA and liver disease. Br Med Bull 1978; 34: 295-300.

4 Scheuer PJ. Liver biopsy interpretation. 3rd ed. London: Ballière Tindell, 1980: 245.

5 Batchelor JR. Assays for cytotoxic and haemagglutinating antibodies against histocompatibility antigens. In: Weir DM, ed. Handbook of experimental immunology. 2nd ed. Oxford: Blackwell, 1973: 32.

6 Galbraith RM, Eddlestone ALWF, Williams $\mathrm{R}$ et al. Enhanced antibody responses to active chronic hepatitis: relation to HLA-B8 and HLA-B12 and portal-systemic shunting. Lancet 1976; 1: 930-4.

7 Eddlestone ALWF, Williams R. Inadequate antibody response to $\mathrm{HBAg}$ or suppressor $\mathrm{T}$-cell defect in development of active chronic hepatitis. Lancet 1974; 2: 1543-5.

8 Mackay IR, Morris PJ. Association of autoimmune active chronic hepatitis with HLA-1,8. Lancet 1972; 2: 793-5.

9 Freudenberg J, Baumann H, Arnold W et al. HLA in different forms of chronic active hepatitis. A comparison between adult patients and children. Digestion 1977; 15: 260-70.

10 Page AR, Sharp HL, Greenberg LJ, Yunis EJ. Genetic analysis of patients with chronic active hepatitis. $J$ Clin Invest 1975; 56: 530-5.

11 Bodmer WF. The HLA system and disease. $J$ Coll Physicians Lond 1980; 14: 43-50.

12 Roseau E. La cholangeite sclerosante primitive. Nouv Presse Med 1978; 28: 2465-7.

13 Fee HJ, Gewirtz H, Schiller J, Longmire WP. Sclerosing cholangitis and primary biliary cirrhosis - a disease spectrum? Ann Surg 1977; 186: 589-93.

14 Hamlyn AN, Adams D, Sherlock S. Primary or secondary sicca complex? Investigation in primary biliary cirrhosis by histocompatibility testing. $\mathrm{Br} \mathrm{Med} \mathrm{J}$ 1980; 281: 425-6.

15 Gleeson FC, Walker JS, Wentzel et al. Human leucocyte antigens in Crohn's disease and ulcerative colitis. Gut 1972; 13: 438-40.

16 Asquith P, Mackintosh P, Stokes PL et al. Histocompatibility antigens in patients with inflammatory bowel disease. Lancet 1974; 1: 113-5.

17 Morgan MY, Ross MGR, Ng CM et al. HLA-B8, immunoglobulins and antibody responses in alcoholrelated liver disease. J Clin Pathol 1980; 33: 488-92. 